\title{
Bacterial vaginosis, the leading cause of genital discharge among women presenting with vaginal infection in Dar es Salaam, Tanzania
}

\author{
Mtebe V Majigo, Paschal Kashindye, Zachariah Mtulo, Agricola Joachim
}

\begin{abstract}
Department of Microbiology and Immunology, Muhimbili University of Health and Allied Sciences Dar es Salaam, Tanzania.
\end{abstract}

\section{Authors' email \\ MM mmajigo@gmail.com; PK paschalkashypaschal@gmail.com; ZM zachariahmtulo@yahoo.co.uk; AJ agricolaj@yahoo.com}

\begin{abstract} vaginal discharge at a regional referral hospital in Dar es Salaam, Tanzania. study participants and the proportion of vaginal infections. business.

Keywords: Bacterial vaginosis, vaginal discharge, genital infection.

DOI: https://dx.doi.org/10.4314/ahs.v21i2.7 ahs.v21i2.7

\section{Introduction}

Vaginal discharge affects millions of women worldwide and has been reported to be among the common complaints of women in reproductive age ${ }^{1,2}$. About a quarter of adult women report this complaint ${ }^{3}$; nevertheless, the discharge may be expected due to slightly overgrowth of naturally occurring vaginal organisms ${ }^{2}$. Vaginal discharge categorized as pathological is characterized by the presence of greenish or yellowish,

\section{Corresponding author: \\ Mtebe Venance Majigo, \\ Muhimbili University of Health and Allied Sciences, \\ P.O. Box 65001, Dar es Salaam, Tanzania, \\ phone - +255754265561 \\ Email: mmajigo@gmail.com}

Background: Pathological vaginal discharge is a common complaint of women in reproductive age worldwide caused by various agents. The prevalence and etiologic agents vary depending on the population studied. Management of vaginal discharge in low-income countries, typically depend on the syndromic approach, which limits understanding the specific causative agents. We determined the proportion of bacterial vaginosis, candidiasis, and trichomoniasis among women with

Methods: We conducted a cross-sectional study between June and August of 2017 among nonpregnant women at Amana Regional Referral Hospital. Experienced staff performed physical examination to establish a clinical diagnosis, and collection of the high vaginal swab for microscopic examination. Descriptive statistics were performed to assess the characteristics of

Results: A total of 196 samples were collected, of all, 128 (65.3\%) had either bacterial vaginosis, candidiasis, or trichomoniasis. Bacterial vaginosis was the leading infection at 33.2\%, followed by candidiasis (19.4\%) and trichomoniasis (13.3\%). Laboratory confirmed vaginal infection were generally found more in age below 25 , unmarried, and those employed or petty

Conclusion: The proportion of bacterial vaginosis in women with vaginal discharge was relatively higher than others, and the presence of vaginal infection relate to span style="font-family:'Times New Roman"'>socio-demographic characteristics. Further advanced studies are needed to understand the potential role of aetiologic agents in causing vaginal infections.

Cita as: Majigo MV, Kashindye P, Mtulo Z, Joachim A. Bacterial vaginosis, the leading cause of genital discharge among women presenting with vaginal infection in Dar es Salaam, Tanzania. Afri Health Sci. 2021;21(2). 531-537. https:/ / dx.doi.org/10.4314/

foul-smelling, and sometimes associated with itching. Bacteria, fungus, and parasites are common causes of vaginal infection associated with pathological vaginal discharge ${ }^{4,5}$. The reported prevalence of vaginal infections varies depending on the population in which the study is conducted ${ }^{5}$.

The majority of vaginal infections are attributable to three causes: bacterial vaginosis (BV), candidiasis, and trichomoniasis ${ }^{6-8}$. The occurrence of $\mathrm{BV}$ has been associated with various factors related to intra-vaginal practices $^{5,9}$, causing depletion Lactobacilli, overgrowth of Gardnerella vaginalis, and overgrowth of anaerobic Gram-negative rods ${ }^{4,10,11}$. Studies in the sub-Saharan Africa region have reported the prevalence of $\mathrm{BV}$ up to $50 \%{ }^{9,12}$. Having BV and trichomoniasis in pregnan- 
cy has been linked to preterm delivery and low birth weight $t^{13}$. Also, vaginal infection is likely to increase the risk of infection with human immunodeficiency virus $(\mathrm{HIV})^{14}$. Various studies have shown that women with BV are more likely to be co-infected with a sexually transmitted viral infection like herpes simplex virus type-2 and HIV ${ }^{15-18}$.

Diagnosis and treatment of BV, candidiasis, and trichomoniasis in most low-income countries rely on the syndromic approach of vaginal discharge syndrome. In Tanzanian women reporting vaginal discharge are managed using the algorithm as per national guidelines for the management of sexually transmitted and reproductive tract infections ${ }^{19}$. The algorithm takes into consideration both common vaginal and cervical infections. The policy requires an aetiologic/laboratory approach at facilities with well equipped functional laboratories like referral facilities. However, in practice, women who present with vaginal discharge syndrome at the outpatient and gynecologic clinic are managed following the syndromic approach. There is a possibility of overtreating a combined vaginal infection, which is mostly symptomatic and easily diagnosed microscopically.

This study determined the proportion of BV, candidiasis, and trichomoniasis, which commonly causes symptomatic vaginal infections. The findings generate data, which can be an input to review the current management approach for vaginal discharge syndrome and the prevention of complications of vaginal infections.

\section{Materials and methods \\ Study setting}

The study was conducted at amana regional referral hospital (arrh) in dar es salaam Tanzania. ARRH serves the population of Ilala Municipal with an approximate of 1,220,611 people as of 2012 census. The hospital has an authorized bed capacity of 362; however, the outpatient attendance ranges between 800-1200 daily. The hospital receives referred cases from the health centers around Ilala Municipal, sometimes from dispensaries and client self-referral.

\section{Study design}

This was a cross-sectional study conducted between June and August 2017 at ARRH in Dar es Salaam, Tanzania. Enrolled participants were examined to establish the clinical diagnosis of vaginal discharge syndrome and investigated for the presence of $\mathrm{BV}$, candidiasis, and trichomoniasis.

\section{Study population}

The study involved women presenting with signs and symptoms suggestive of vaginal infections at outpatient and gynecological clinics. The symptoms included perceived abnormal vaginal discharge which has different color, odor, consistency or amount than normal discharge and vaginal itching. Routinely, similar cases are examined by attending clinicians to establish the clinical diagnosis of vaginal discharge syndrome before initiation of treatment. For this study, women with symptoms of vaginal discharge syndrome and observed abnormal vaginal discharge and vaginal wall inflamantion the features suggestive of vaginal infection upon physical examination were requested to participate in the study. The study enrolled participants after provide written consent for the collection of high vaginal swab specimens. The study included women with age of 18 years and above excluding women who were pregnant, menstruating, and who had started antibiotics

\section{Sample size and sampling technique}

The sample size was estimated using Kish Leslie formula $^{20}$, at a $95 \%$ confidence interval considering $15 \%$ prevalence of pathological vaginal discharge among women at the gynecology clinic $^{7}$ and a $5 \%$ margin of error. Eligible clients were consecutively enrolled in the study until reaching a representative sample size.

\section{Specimen and Data collection}

A high vaginal swab specimen was aseptically collected by attending clinician or specialized nurse. A standard speculum examination was performed for each participant using sterile Cusco's speculum without lubricant. Macroscopic evaluation of the vaginal walls for color, amount and consistency of the discharge were noted A sterile cotton swab (H-Media Ltd, India) was used to collect specimens from the posterior fornix of the vagina and then placed in commercially available Amies transport medium (H-Media Ltd, India), labeled with the specific identification number. Specimens were transported at ambient temperature to the Microbiology laboratory at the Muhimbili University of Health and Allied Sciences for further processing within 12 hours. Participants' information regarding socio-demographic characteristics, including age, marital status, occupation, and level of education were obtained from patients' files and laboratory request form.

\section{Laboratory investigations}

Wet-mounts made from the swabs in transport media were examined for motile trichomonads by light mi- 
croscopy using high dry power (x 40). The diagnosis of trichomoniasis was reached after detecting Trichomonas vaginalis, recognized by their jerky movements, undulating membrane, and possession of four flagella.

The smears were made, Gram-stained, and scored for BV by an experienced laboratory technologist according to Nugent's criteria as previously described ${ }^{21}$. Three types of bacterial morphotypes were evaluated: large gram-positive rods, small gram-negative/variable rods, and curved gram variable rods. A Nugent score of $0-3$ was interpreted as negative, a score of 4-6 as intermediate, while a score of $7-10$ was interpreted as consistent with BV.

The same Gram-stained smears were examined for the presence of Gram-positive budding yeast cells. A diagnosis of Candida spp as the etiological agent was based on the presence of Gram-positive yeast cells and a clinical diagnosis of vulvovaginal candidiasis and thick curdy vaginal discharge.

\section{Quality control}

The laboratory procedures were performed by following the established standard operating procedures. Quality assurance procedures were set during specimen collection, smear preparation, staining, and microscopic examination. Quality of stains was tested on each day of use with both positive and negative control smears for BV and Candida spp.

\section{Data analysis}

Conventional descriptive statistics were used to assess the characteristics of study participants and the proportion of vaginal infections. A Chi-square test was used to determine whether there were significant differences between observed proportions of vaginal infections in the studied population. The differences of socio-demographic characteristics with $\mathrm{BV}$, candidiasis, and trichomoniasis were made using the Pearson Chi-square test with a test of significance being two-tailed $(p<0.05)$. Data were analyzed using Statistical Package for Social Sciences version 20.0

\section{Results}

\section{Socio-demographic characteristics}

A total of 196 participants had high vaginal swabs specimen collected; the median age was 29 years, 25.0 - 34.7 years inter-quartile range (IQR). The majority, $111(56.6 \%)$ were aged between $25-35$ years, and $137(69.9 \%$ ) had low education (primary obelow education level). More than half of participants, 116 (59.2\%) engaged in petty businesses ( independently owned small business) while $151(77.0 \%)$ were married (Table 1)

Table 1: Socio-demographic characteristics of 196 study participants

\begin{tabular}{lll}
\hline Characteristics & Frequency & Percentages (\%) \\
\hline Age group & & \\
$<25$ & 43 & 21.9 \\
$25-35$ & 111 & 56.6 \\
$>35$ & 42 & 21.4 \\
Education & & \\
Low & 137 & 69.9 \\
High & 59 & 30.1 \\
Occupation & & \\
Housewife & 68 & 34.7 \\
Petty business & 116 & 59.2 \\
Employed & 12 & 6.1 \\
Marital status & & \\
Married & 151 & 77.0 \\
Single & 45 & 23.0 \\
\hline
\end{tabular}

\section{Vaginal infections}

Of all, $128(65.3 \%, 95 \%$ CI, 58.4-71.6) had one of the three vaginal infections (BV, candidiasis, trichomoniasis)). BV was the leading infection with $65(33.2 \%, 95 \%$
CI, 26.9-40.0) followed by candidiasis (38(19.4\%, 95\% CI, 14.4-25.5). Mixed infection was observed only in $1(0.5 \%)$ participant having candidiasis and trichomoniasis (Table 2) 
Table 2: Proportion of participants with positive results of vaginal infection among 196 Participants

\begin{tabular}{lcc}
\hline Infection & Proportion (\%) & 95\% CI of Proportion \\
\hline Total vaginal infection & $128(65.3)$ & $58.4-71.6$ \\
Bacterial vaginosis & $65(33.2)$ & $26.9-40.0$ \\
Candidiasis & $38(19.4)$ & $14.4-25.5$ \\
Trichomoniasis & $26(13.3)$ & $09.2-18.7$ \\
Candidiasis & $1(0.5)$ & \\
+ Trichomoniasis & & \\
\hline
\end{tabular}

Vaginal infection and socio-demographic Characteristics

The differences in vaginal infection with socio-demographic characteristics are shown in table 3. Patients dealing with the petty business had a significantly higher proportion of BV $(46.6 \%)$ than other occupations $(\mathrm{p}<$ 0.01). Those who were married had more BV (38.4\%) compared to single $7(15.6 \%)$ ( $p<0.01)$. There was no difference in the proportion of $\mathrm{BV}$ in different education levels and age groups.

The significant difference of candidiasis in different socio-demographic characteristics was observed only for types of participant's occupation. Employed participants had more infection with candidiasis $(50 \%)$ than Housewife (27.9\%), and Petty business (11.2\%), p < 0.01).

Trichomoniasis was observed more in the age group below 25 years $(30 \%)$, single marital status $(53.3 \%)$, and petty business $(19.8 \%)$ than other characteristics in the same categories, and the differences were statically significant $(p<0.01)$. There was no sinificant difference proportion of any vaginal infections with the level of educations. There was an association between the presence of at least one vaginal infection and age group, marital status as well as an occupation $(\mathrm{p}<0.05)$ (Table 3)

Table 3: Bacterial vaginosis, Candidiasis, and trichomoniasis and sociodemographic characteristics of study participants

\begin{tabular}{|c|c|c|c|c|c|c|c|c|}
\hline \multirow[t]{2}{*}{ variable } & \multicolumn{2}{|c|}{ B. Vaginosis } & \multicolumn{2}{|c|}{ Candidiasis } & \multicolumn{2}{|c|}{ Trichomoniasis } & \multicolumn{2}{|c|}{ Vaginal infection* } \\
\hline & $\mathbf{N}(\%)$ & p value & $\mathbf{N}(\%)$ & p value & $\mathbf{N}(\%)$ & p value & $\mathbf{N}(\%)$ & p value \\
\hline Age (years) & & 0.89 & & 0.44 & & $<0.01$ & & 0.042 \\
\hline Below 25 & $14(32.6)$ & & $8(18.6)$ & & $13(30.2)$ & & $35(81.4)$ & \\
\hline $25-35$ & $36(32.4)$ & & $19(17.1$ & & $13(11.7)$ & & $67(60.4)$ & \\
\hline Above 35 & $15(35.7)$ & & $11(26.2)$ & & 0 & & $26(61.9)$ & \\
\hline $\begin{array}{l}\text { Marital Status } \\
\text { single }\end{array}$ & $7(15.6)$ & 0.004 & $7(15.6)$ & 0.46 & $24(53.3)$ & $<0.001$ & $37(82.2)$ & 0.007 \\
\hline Married & $58(38.4)$ & & $31(20.5)$ & & $2(1.3)$ & & $91(60.3)$ & \\
\hline Occupation & & $<0.001$ & & $<0.001$ & & 0.002 & & $<0.001$ \\
\hline Housewife & $8(11.8)$ & & $19(27.9)$ & & $1(1.5)$ & & $28(41.2)$ & \\
\hline Petty business & $54(46.6)$ & & $13(11.2)$ & & $23(19.8)$ & & $89(76.7)$ & \\
\hline Employed & $3(25.0)$ & & $6(50.0)$ & & $2(16.7)$ & & 11(91.7) & \\
\hline Education & & 0.71 & & 0.57 & & 0.70 & & 0.878 \\
\hline Low level & $43(31.4)$ & & $28(20.4)$ & & $19(13.9)$ & & $89(65.0)$ & \\
\hline High level & $22(37.3)$ & & $10(16.9)$ & & $9(11.9)$ & & $39(66.1)$ & \\
\hline
\end{tabular}

\section{Discussion}

The current study on vaginal infection among women with vaginal discharge reports a relatively higher proportion of BV compared to candidiasis and trichomoniasis. Almost every individual except one had a single infectious condition of the three common causes of vaginal infection. About one-third of participants had unidentified etiology of vaginal discharge. These findings necessitate the need for looking into other etiological agentsthat may lead to vaginitis since etiologies of genital tract infections may vary widely. ${ }^{22}$. The finding of $\mathrm{BV}$ being the most common etiologic condition of vaginal discharge followed by candidiasis was coherent with findings from other studies investigating vaginal 
infection ${ }^{23-25}$. Our findings, however, differ from the finding of previous research in the same location'. Candidiasis, followed by $\mathrm{BV}$ as the most prevalent vaginal infection, was reported in studies conducted in Ethiopia and India, 26. The differences observed in different studies can be explained by the difference in the actual study participants, personal hygiene practice, environment, socioeconomic and cultural factors of the study participants.

The prevalence of $\mathrm{BV}$ in the present study was comparable with various studies that reported a relatively high prevalence of $\mathrm{BV}$, ranging from $26 \%$ to $34 \%{ }^{27-29}$. However, some studies have reported a low prevalence of $\mathrm{BV}$ to compare to our findings $\mathrm{s}^{7,30,31}$. The variations in the prevalence of $\mathrm{BV}$ reported in different studies may be attributed by differences in study population and method used for the detection of bacterial vaginosis ${ }^{26}$, 32,33. The magnitude of BV in this study might indicate a high rate of disturbance of normal genital microbial flora that led to the proliferation of pathogenic organisms. Women in this community might be practicing intra-vaginal practices as the previous report indicated a high rate of vaginal douching associated with increased prevalence of BV9.

Trichomoniasis was the least observed in our study compared to other vaginal infections but slightly higher than earlier reports in the same geographical location9 and other parts of the world ${ }^{26,34,35}$. A study done among pregnant women in Botswana reported a higher prevalence of $19 \%$ for trichomoniasis ${ }^{36}$. The differences of trichomoniasis found in different studies could be due to variations in personal hygiene practice, socioeconomic, and cultural factors of the study participants. Moreover, the detection of Trichomonas vaginalis by the conventional wet-mount method in the present study might have reduced the actual prevalence ${ }^{37}$.

The proportion of vaginal infection by either BV, Candidiasis, or trichomoniasis was found to vary in participants' marital status, occupation, and age groups. Married participants had a significantly higher proportion of BV. The finding is coherent with a study done in Egypt $^{27}$. On the contrary, the study done in Nepal found that unmarried women were at higher risk compared to married women ${ }^{38}$. Likewise, BV has been found in sexually inactive females ${ }^{39,40}$, signifying the presence of other factors rather than sexual activity alone as the risk for acquisition of BV. In the present study, trichomoniasis was observed more in the age group below 25 years and those who were single. Our finding of age in relation to trichomoniasis was comparable to a study done in Ethiopia ${ }^{7}$ and $\operatorname{Iran}^{35}$.

This was a small study with limited data for factors contributing to vaginal infection and for evidently establish the reason for different observations found among participants, even though some findings are coherent or contrary to other studies. In this study, we relied on microscopic methods of detecting BV, candidiasis, and trichomoniasis. Using the culture method could have been more accurate than the microscopic examination.

\section{Conclusion}

There is a relatively high proportion of bacterial vaginosis among nonpregnant women and could be affected by certain socio-demographic characteristics. We recommend further longitudinal and follow-up studies to investigate the effect of infection and the role of $\mathrm{BV}$, candidiasis, and trichomoniasis in causing vaginal infections.

\section{Abbreviations \\ ARRH: Amana Regional Referral Hospital, BV: bacteri- al vaginosis, HIV: human immunodeficiency, VC: vagi- nal candidiasis, TV: Trichomonas vaginalis}

\section{Ethics approval and consent to participate}

Ethical clearance was obtained from the Senate Research and Publications Committee of the Muhimbili University of Health and Allied Sciences in Dar es Salaam, Tanzania. Administrative permission for the study was granted by the Ilala Municipal Health authorities in Dar es Salaam city and Amana Regional Referral Hospital Management. All participants provided informed consent for Data and specimen collection for further analysis. The confidentiality of the information obtained was maintained throughout the study.

\section{Consent for publication}

Not applicable

\section{Competing interests}

The authors declare that they have no competing interests

\section{Authors' contributions}

$\mathrm{MM}$, and PK participated in the conception and designing of the study. PK participated in data collection, PK and ZM performed laboratory tests. MM and AJ analyzed, interpreted the data, and participated in the writing of the manuscript. All authors read and approved the final version of the document. 


\section{Acknowledgment}

We are thankful to clients who agreed to participate in the study. Thanks to clinicians and nursing staff at the reproductive health clinic and gynecologic ward at Amana Regional Referal Hospital in Dar es Salaam who assisted in specimen collection. Lastly, we acknowledge the contribution of laboratory technicians at Amana Regional Referral Hospital laboratory, and Department of Microbiology and Immunology, Muhimbili University College of health and allied Sciences who performed laboratory procedures.

\section{References}

1. Rizvi N, Luby S: Vaginal discharge: perceptions and health-seeking behavior among Nepalese women. J Pak Med Assoc 2004, 54(12):620-624.

2. Trollope-Kumar K: Cultural and biomedical meanings of the complaint of leukorrhea in South Asian women. Trop Med Int Health 2001, 6(4):260-266.

3. Koenig M, Jejeebhoy S, Singh S, Sridhar S: Investigating women's s gynaecological morbidity in India: Not just another KAP survey. Reproductive health Matters 1998, 6(11):84-97.

4. Kent HL: Epidemiology of vaginitis. Am J Obstet Gynecol 1991, 165(4 Pt 2):1168-1176.

5. Tempera G: Vaginal infections: epidemiology and risk factors.27.7/8 (2005): Giornale Italiano di Ostetricia e Ginecologia 2005, 27(7-8):280-283.

6. Gupta G NS, Agarwal A.: Prevalence of candidiasis, trichomoniasis, and bacterial vaginosis among women of reproductive age group. Indian Journal of Public Health Research \& Development 2013, 4(2):94-98.

7. Mulu W, Yimer M, Zenebe Y, Abera B: Common causes of vaginal infections and antibiotic susceptibility of aerobic bacterial isolates in women of reproductive age attending at Felegehiwot referral Hospital, Ethiopia: a cross-sectional study. BMC Women's Health, 2015, 15(1):42.

8. Narayankhedkar A, Hodiwala A, Mane A: Clinicoetiological Characterization of Infectious Vaginitis amongst Women of Reproductive Age Group from Navi Mumbai, India. J Sex Transm Dis 2015:817092.

9. Majigo M MF, Manyahi J, Aboud S, Mshana S, Urassa W.: Microbial Aetiology of Vaginal Discharge in Relation to Intra-Vaginal Practices among Women Attending Reproductive Health Clinic in Dar es Salaam, Tanzania. International Journal of Health Sciences and Research (IJHSR) 2015, 5(5):164-172.

10. Hill GB: The microbiology of bacterial vaginosis. Am J Obstet Gynecol 1993, 169(2 Pt 2):450-454.

11. Cauci S, Driussi S, De Santo D, Penacchioni P, Iannicelli T, Lanzafame P, De Seta F, Quadrifoglio F, de
Aloysio D, Guaschino S: Prevalence of bacterial vaginosis and vaginal flora changes in peri- and postmenopausal women. J Clin Microbiol 2002, 40(6):2147-2152. 12. Demba E, Morison L, van der Loeff MS, Awasana AA, Gooding E, Bailey R, Mayaud P, West B: Bacterial vaginosis, vaginal flora patterns and vaginal hygiene practices in patients presenting with vaginal discharge syndrome in The Gambia, West Africa. BMC Infect Dis 2005, 5:12.

13. Riggs MA, Klebanoff MA: Treatment of vaginal infections to prevent preterm birth: a meta-analysis. Clin Obstet Gynecol 2004, 47(4):796-807; discussion 881-792.

14. Grosskurth H, Mosha F, Todd J, Mwijarubi E, Klokke A, Senkoro K, Mayaud P, Changalucha J, Nicoll A, ka-Gina $G$, et al.: Impact of improved treatment of sexually transmitted diseases on HIV infection in rural Tanzania: a randomized controlled trial. Lancet 1995, 346(8974):530-536.

15. Cherpes TL, Meyn LA, Krohn MA, Hillier SL: Risk factors for infection with herpes simplex virus type 2 : role of smoking, douching, uncircumcised males, and vaginal flora. Sex Transm Dis 2003, 30(5):405-410.

16. Martin HL, Richardson BA, Nyange PM, Lavreys L, Hillier SL, Chohan B, Mandaliya K, Ndinya-Achola JO, Bwayo J, Kreiss J: Vaginal lactobacilli, microbial flora, and risk of human immunodeficiency virus type 1 and sexually transmitted disease acquisition. $J$ Infect Dis 1999, 180(6):1863-1868.

17. Moodley P, Connolly C, Sturm AW: Interrelationships among human immunodeficiency virus type 1 infection, bacterial vaginosis, trichomoniasis, and the presence of yeasts. J Infect Dis 2002, 185(1):69-73.

18. Sewankambo N, Gray RH, Wawer MJ, Paxton L, McNaim D, Wabwire-Mangen F, Serwadda D, Li C, Kiwanuka N, Hillier SL et al.: HIV-1 infection associated with abnormal vaginal flora morphology and bacterial vaginosis. Lancet 1997, 350(9077):546-550.

19. NACP: National guidelines for the management of sexually transmitted and reproductive tract infections First Edition, March 2007. In.: www.nacp.go.tz/site/ download/stinationalguideline.pdf; 2007.

20. Israel GD: Determining sample size. 1992.

21. Nugent RP, Krohn MA, Hillier SL: Reliability of diagnosing bacterial vaginosis is improved by a standardized method of gram stain interpretation. J Clin Microbiol 1991, 29(2):297-301.

22. Aboud S, Msamanga G, Read J, Mwatha A, Chen Y, Potter D, Valentine M, Sharma U, Hoffmann I, Taha TE: Genital tract infections among HIV-infected pregnant women in Malawi, Tanzania and Zambia. International Journal of STD \& AIDS 2008, 19(12):824-832.

23. Bradshaw CS, Morton AN, Garland SM, Mor- 
ris MB, Moss LM, Fairley CK: Higher-risk behavioral practices associated with bacterial vaginosis compared with vaginal candidiasis. Obstetrics \& Gynecology 2005, 106(1):105-114.

24. Xueqiang F, Yingzhi Z, Yanfang Y, Yutao D, Huiqing L: Prevalence and risk factors of trichomoniasis, bacterial vaginosis, and candidiasis for married women of child-bearing age in rural Shandong. Japanese Journal of Infectious Diseases 2007, 60(5):257.

25. Brotman RM, Klebanoff MA, Nansel TR, Andrews WW, Schwebke JR, Zhang J, Yu KF, Zenilman JM, Scharfstein DO: A longitudinal study of vaginal douching and bacterial vaginosis - a marginal structural modeling analysis. American Journal of Epidemiology 2008, 168(2):188-196.

26. Mulu W, Yimer M, Zenebe Y, Abera B: Common causes of vaginal infections and antibiotic susceptibility of aerobic bacterial isolates in women of reproductive age attending at Felegehiwot Referral Hospital, Ethiopia: a cross-sectional study. BMC Womens Health, 2015, 15:42.

27. Gad ${ }^{1}$ GF, El-Adawy AR, Mohammed MS, Ahmed AF, Mohamed ${ }^{1}$ HA: Evaluation of different diagnostic methods of bacterial vaginosis. 2014.

28. Group NCHSPT: Prevalence of bacterial vaginosis among young women in low-income populations of coastal Peru. International Journal of STD \& AIDS 2007, 18(3):188-192.

29. Shayo PA, Kihunrwa A, Massinde AN, Mirambo M, Rumanyika RN, Ngwalida N, Gumodoka B, Kidola J, Magoma M: Prevalence of bacterial vaginosis and associated factors among pregnant women attending at Bugando Medical Centre, Mwanza, Tanzania. Tanzania Journal of Health Research 2012, 14(3).

30. Anh PK, Khanh NTN, Ha DT, Chien DT, Thuc PT, Luong PH, Kilmarx PH, Wongchotigul V, Kitayaporn D, Rowe PJ: Prevalence of lower genital tract infection among women attending maternal and child health and family planning clinics in Hanoi, Vietnam. SoutbEast Asian Journal of Tropical Medicine and Public Health 2003, 34(2):367-373.

31. Manandhar R, Sharma J, Shrestha BPB, Pradhan N:
14. Bacterial vaginosis in Tribhuvan University Teaching Hospital. Journal of Institute of Medicine 2007, 27(2).

32. Muvunyi CM, Hernandez TC: Prevalence of bacterial vaginosis in women with vaginal symptoms in South Province, Rwanda. African Journal of Clinical and Experimental Microbiology 2009, 10(3).

33. Rao PS, Devi S, Shriyan A, Rajaram M, Jagdishchandra K: Diagnosis of bacterial vaginosis in a rural setup: comparison of clinical algorithm, smear scoring, and culture by semiquantitative technique. Indian J Med Microbiol 2004, 22(1):47-50.

34. Abdelaziz ZA, Ibrahim ME, Bilal NE, Hamid ME: Vaginal infections among pregnant women at Omdurman Maternity Hospital in Khartoum, Sudan. The Journal of Infection in Developing Countries 2014, 8(04):490-497. 35. Kadir M, Sulyman M, Dawood I, Shams-Eldin S: Trichomonas vaginalis and associated microorganisms in women with vaginal discharge in Kerkuk-Iraq. Ankara Medical Journal, 2014, 14(3).

36. Romoren M, Velauthapillai M, Rahman M, Sundby J, Klouman E, Hjortdahl P: Trichomoniasis and bacterial vaginosis in pregnancy: inadequately managed with the syndromic approach. Bull World Health Organ, 2007, 85(4):297-304.

37. Mason P, Super H, Fripp P: Comparison of four techniques for the routine diagnosis of Trichomonas vaginalis infection. Journal of Clinical Pathology 1976, 29(2):154-157.

38. Ranjit E, Raghubanshi BR, Maskey S, Parajuli P: Prevalence of bacterial vaginosis and its association with risk factors among nonpregnant women: A hospital-based study. International Journal of Microbiology 2018, 2018.

39. Vaca M, Guadalupe I, Erazo S, Tinizaray K, Chico M, Cooper P, Hay P: High prevalence of bacterial vaginosis in adolescent girls in a tropical area of Ecuador. BJOG: An International Journal of Obstetrics \& Gynaecology 2010, 117(2):225-228.

40. Yen S, Shafer M-A, Moncada J, Campbell CJ, Flinn $\mathrm{SD}$, Boyer CB: Bacterial vaginosis in sexually experienced and non-sexually experienced young women entering the military. Obstetrics \& Gynecology 2003, 102(5):927-933. 